\title{
Post-menopausal breast fibroadenoma - a point of view
}

\author{
Ana Valea ${ }^{1,2}$, Florica Sandru,3,4, Simona Elena Albu ${ }^{3,5}$, \\ Mihai Cristian Dumitrascu ${ }^{3,5}$, Mara Carsote ${ }^{3,6}$ \\ ${ }^{1}$ Clinical County Hospital, Cluj-Napoca, Romania \\ 2"Iuliu Hatieganu" University of Medicine and Pharmacy, Cluj-Napoca, Romania \\ 3"Carol Davila" University of Medicine and Pharmacy, Bucharest, Romania \\ ${ }^{4}$ Elias Emergency University Hospital, Bucharest, Romania \\ ${ }^{5}$ Emergency University Hospital, Bucharest, Romania \\ 6"C.I. Parhon" National Institute of Endocrinology, Bucharest, Romania
}

\begin{abstract}
Breast fibroadenoma is a benign tumour that is mostly asymptomatic thus it may be detected as an incidentaloma. Typically they are diagnosed in women of reproductive age and they reduce the dimensions during menopause because of estrogens deficiency that is why in menopause are rare. The mass is elastic, mobile and it contains an epithelial part and a stromal component (so called fibroepithelial tumours). Here is the case of a 70-year old female who had done a mammogram for the first time and she was found with such a lesion of 1.5 $\mathrm{cm}$. She also is confirmed with osteopenia, most probable unrelated to the breast tumour. Menopausal fibroadenoma, even at low risk of malignancy requires a good multidisciplinary team of decision. Because of the differential diagnosis with breast cancer the positive diagnostic is based on ultrasound, mammogram and even biopsy. Menopausal fibroadenoma, even at low risk of malignancy requires a good multidisciplinary team of decision. Because of the differential diagnosis with breast cancer the positive diagnostic is based on ultrasound, mammogram and even biopsy. Due to low aggressive profile, the follow-up is, however, the most rational approach.
\end{abstract}

Keywords: menopause, fibroadenoma, breast tumor

\section{INTRODUCTION}

Breast fibroadenoma is a benign tumour that is mostly asymptomatic thus it may be detected as an incidentaloma (1). Incidental findings are more frequent in modern era including at breast level, even the term of incidentaloma is commonly used for adrenals and pituitary glands for masses of either solid, either cystic, either mix $(1,2)$. For pituitary incidentaloma surgical removal is not usually an option, for adrenals this may be operational depending on size, speed of growth and positive endocrine activity while for breast incidental findings the management is extremely heterogenous $(1,3,4)$. Fibroadenoma is not accompanied by pain, usually it has a solid structure (not cystic) $(5,6,7)$. Large lesions are clinically accessible as lumps $(5,6,7)$. Typically they are diagnosed in women of reproductive age and they reduce the dimensions during menopause because of estrogens deficiency that is why in menopause are rare $(5,6,7)$. The mass is elastic, mobile and it contains an epithelial part and a stromal component (so called fibroepithelial tumours) $(5,6,7)$.

\section{AIM}

Some aspects of menopausal breast fibroadenoma are introduced.

\section{METHOD}

This is a point of view.

\section{CASE PRESENTATION}

This is a 70 year old female who was referred for non-specific bone pain. The medical family and 
personal history is negative. Thyroid check-up was done and found normal. Mineral metabolism evaluation was normal, including a 25 -hydroxyvitami D of $32 \mathrm{ng} / \mathrm{ml}$ (normal of less than $30 \mathrm{ng} / \mathrm{ml}$ ). Dual-Energy X-Ray Absorptiometry (DXA) showed osteopenia (Figure $1 \mathrm{a}, \mathrm{b}, \mathrm{c}$ ). Screening mammogram was done for the first time in life and it showed right breast opacity, of round-oval form, of 1.5 by 1 by $0.6 \mathrm{~cm}$, which is well shaped and deformable during examination with a homogenous structure (Figure 2). The paraclinical aspects were highly suggestive for a fibroadenoma thus the patient was followed up for the moment. The patient had a mammogram done one year later and the mammary mass was stationary (Figure 3).

\section{DISCUSSION}

A part from clinical evaluation which may be unrevealing, breast ultrasound, mammogram, and biopsy (like core needle biopsy) may be useful un- less surgical removal is done and thus it provides the histological profile $(5,6,8)$. The tumour size varies while more aggressive phenotype are described as hyperplastic, juvenile (between 10 and 18 years), giant (requiring surgery), and phyllodes (which can be malignant and it needs surgery) $(1,9)$. In this case the small dimensions require for the moment serial imaging techniques of follow-up. Also the presence osteopenia seem incidental and generally the benign breast lesions are not associated with a higher risk of bone loss (10).

\section{CONCLUSIONS}

Menopausal fibroadenoma, even at low risk of malignancy, requires a good multidisciplinary team of decision. Because of the differential diagnosis with breast cancer the positive diagnostic is based on ultrasound, mammogram and even biopsy. Due to low aggressive profile, the follow-up is, however, the most rational approach.

Conflict of interest: none declared Financial support: none declared

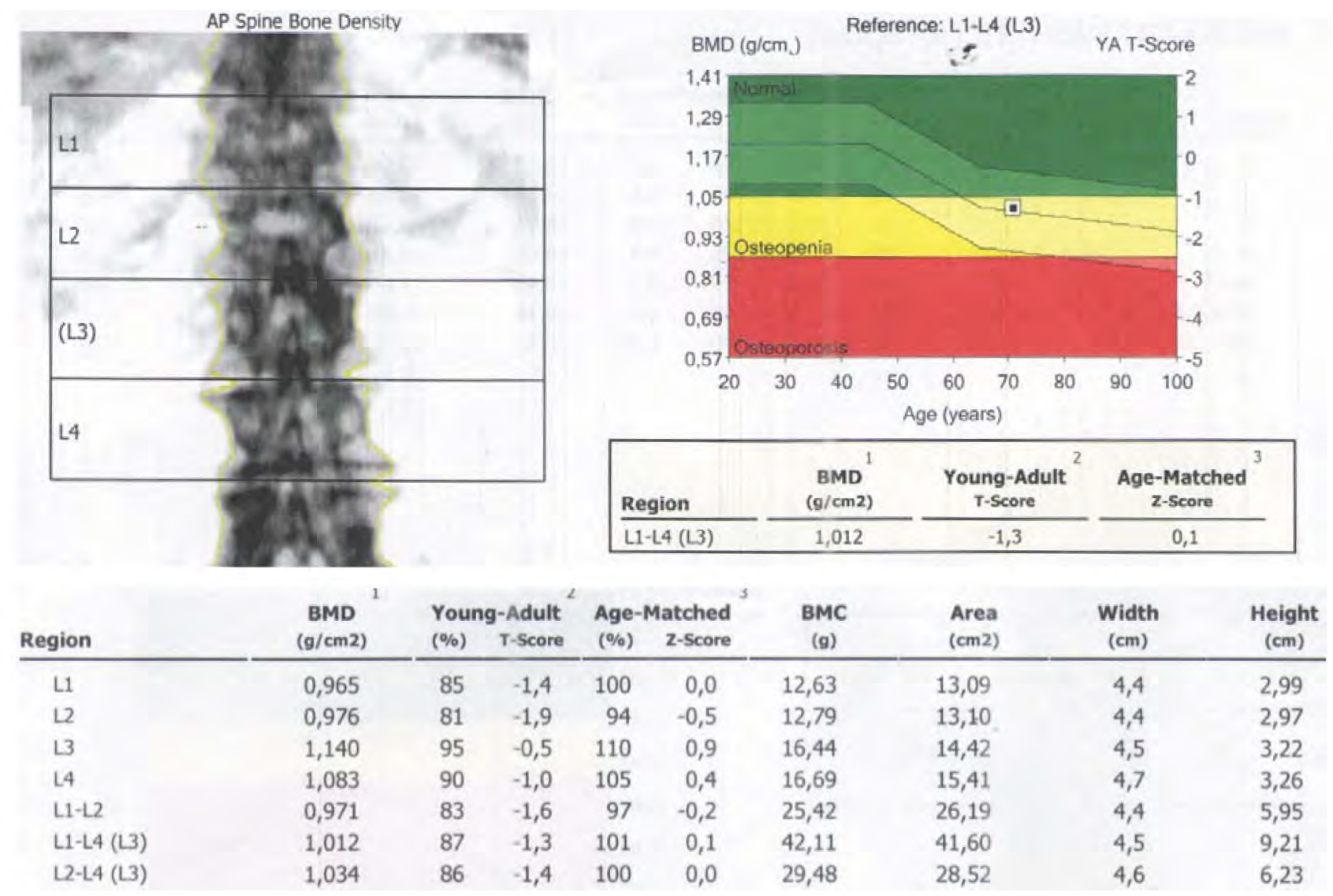

FIGURE 1a . Central DXA on a 70-year old female with osteopenia - Lumbar spine 

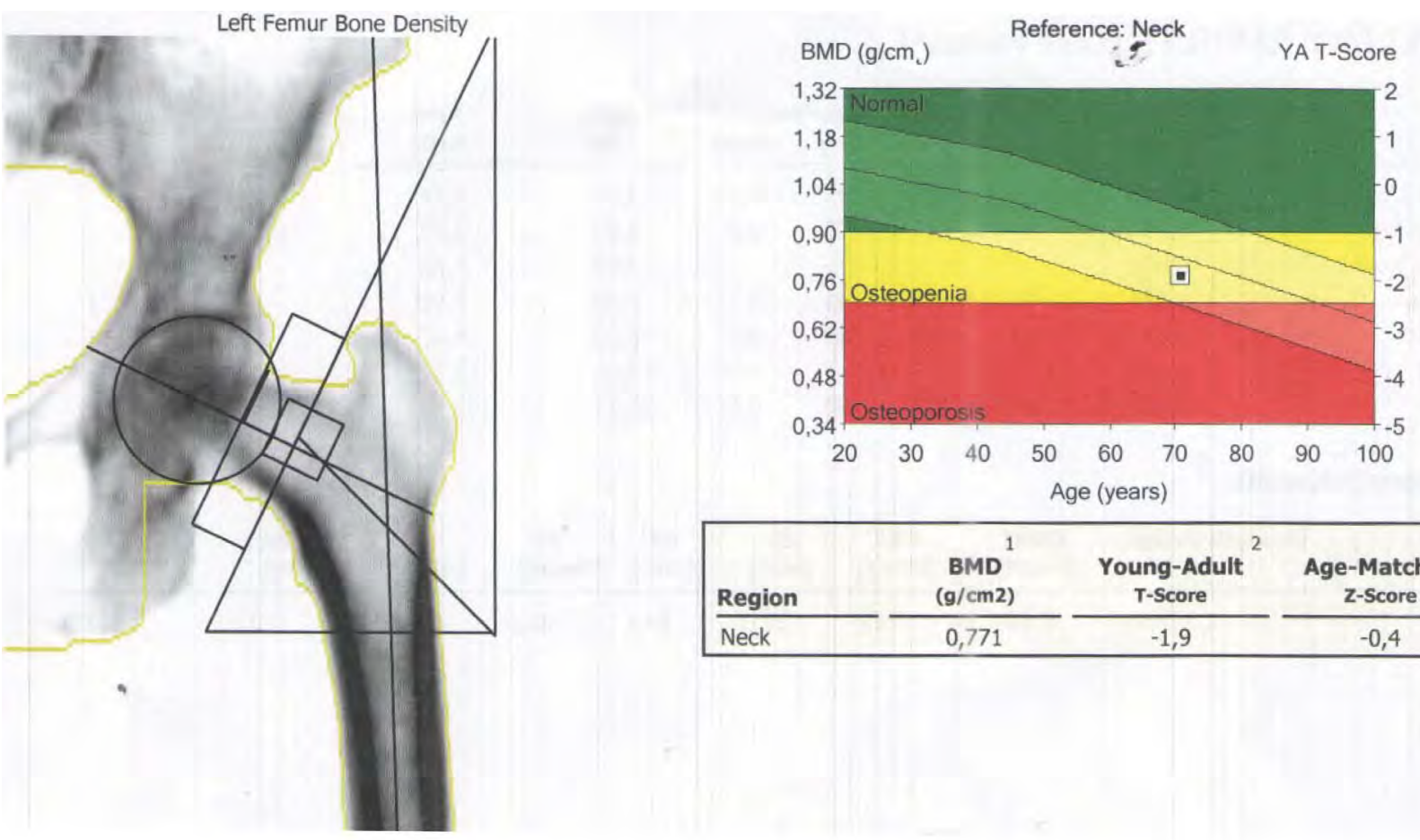

$\frac{\text { Region }}{\text { Neck }} \frac{\begin{array}{c}\text { BMD } \\ \text { (g/cm2) }\end{array}}{0,771} \frac{\begin{array}{c}\text { Young-Adult }^{2} \\ \text { T-Score }\end{array}}{-1,9} \frac{\begin{array}{c}\text { Age-Matched }^{3} \\ \text { Z-Score }\end{array}}{-0,4}$

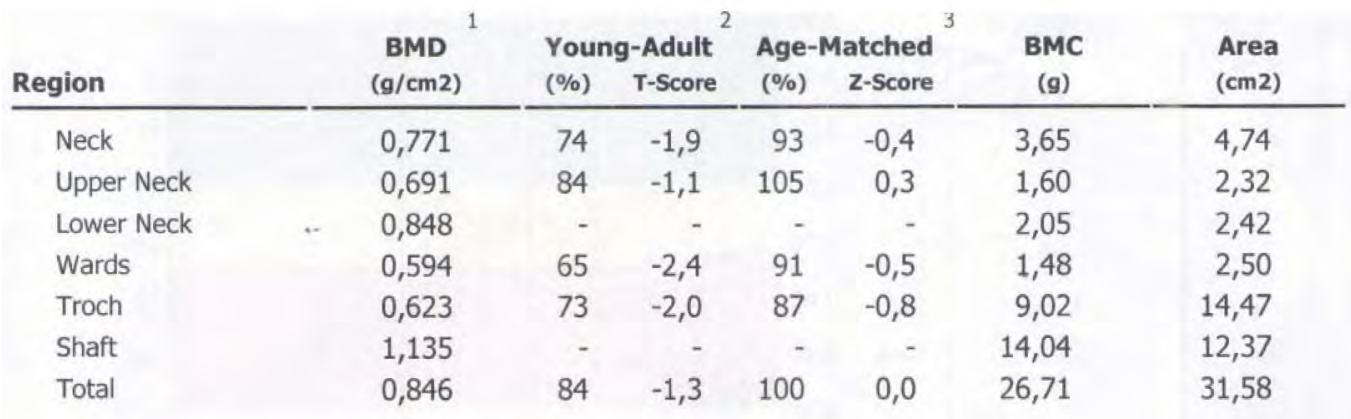

Hip Strength Results ${ }^{4}$

\begin{tabular}{|c|c|c|c|c|c|c|c|c|c|}
\hline Side & Strength Index & $\begin{array}{c}\text { CSMI } \\
(\mathrm{mm} 4)\end{array}$ & $\underset{(\mathrm{mm} 2)}{\mathrm{CSA}}$ & $\begin{array}{c}\text { d1 } \\
(\mathrm{mm})\end{array}$ & $\underset{(\mathrm{mm})}{\mathrm{d} 2}$ & $\begin{array}{c}\mathrm{d} 3 \\
(\mathrm{~mm})\end{array}$ & $\underset{(\mathbf{m m})}{y}$ & $\begin{array}{l}\text { alpha } \\
\text { (deg) }\end{array}$ & $\begin{array}{l}\text { theta } \\
\text { (deg) }\end{array}$ \\
\hline Left & 1,5 & 7.138 & 113 & 13,3 & 54,1 & 31,6 & 15,0 & -2 & 117 \\
\hline
\end{tabular}

FIGURE 1b. Central DXA on a 70-year old female with osteopenia - Femoral neck 

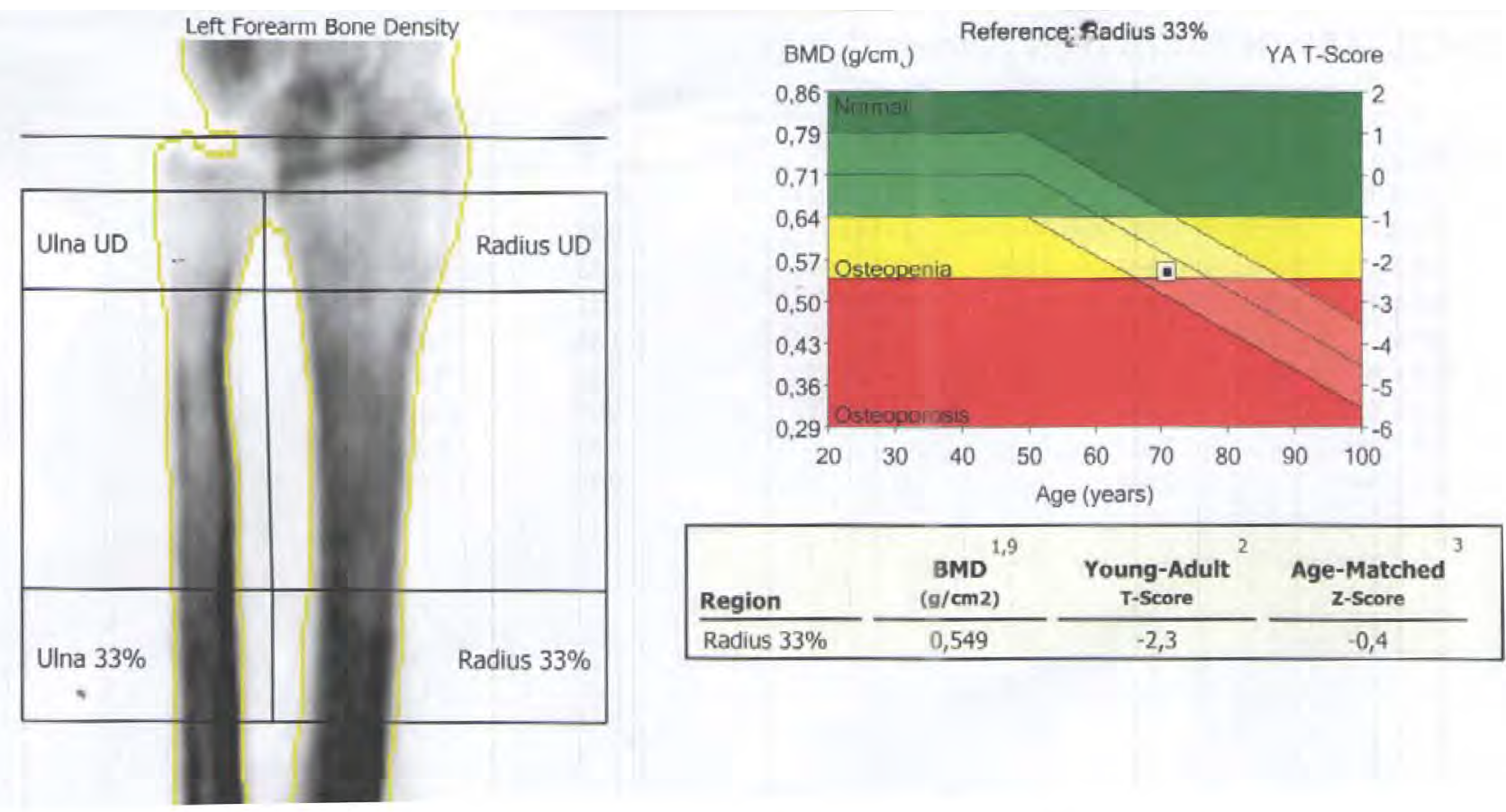

\begin{tabular}{|c|c|c|c|c|c|c|c|}
\hline Region & ${ }_{(\mathrm{g} / \mathrm{cm} 2)}$ & \multicolumn{2}{|c|}{ Young-Adult ${ }^{2}$} & \multicolumn{2}{|c|}{ Age-Matched } & ${ }_{\text {(g) }}{ }^{9}{ }^{9}$ & $\begin{array}{l}\text { Area } \\
(\mathrm{cm} 2)\end{array}$ \\
\hline Radius UD & 0,266 & 71 & $-3,0$ & 86 & $-1,1$ & 1,01 & 3,81 \\
\hline Ulna UD & 0,206 & - & - & - & - & 0,43 & 2,09 \\
\hline Radius 33\% & 0,549 & 77 & $-2,3$ & 95 & $-0,4$ & 1,53 & 2,79 \\
\hline Ulna 33\% & 0,604 & - & - & - & - & 1,15 & 1,90 \\
\hline Both UD & 0,245 & - & - & - & - & 1,44 & 5,90 \\
\hline Both $33 \%$ & 0,571 & - & - & - & - & 2,68 & 4,69 \\
\hline Radius Total & 0,422 & 77 & $-2,6$ & 92 & $-0,7$ & 5,73 & 13,56 \\
\hline Ulna Total & 0,417 & - & - & - & - & 3,43 & 8,22 \\
\hline Both Total & 0,420 & - & - & - & - & 9,16 & 21,78 \\
\hline
\end{tabular}

FIGURE 1c. Central DXA on a 70-year old female with osteopenia - 1/3 distal radius 

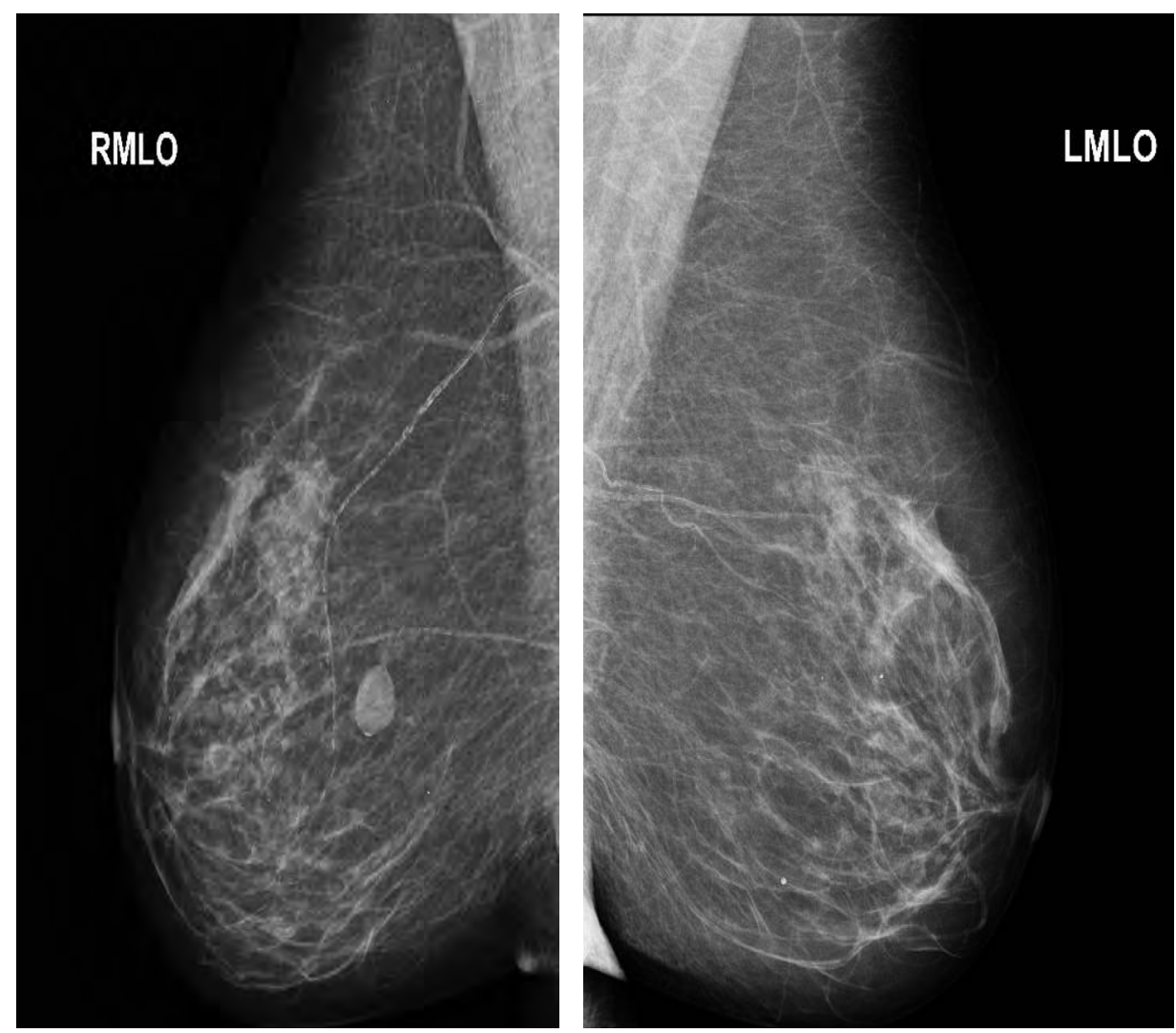

Right breast tumour

Left breast

FIGURE 2. 70-year old female with unilateral aspect at mammogram
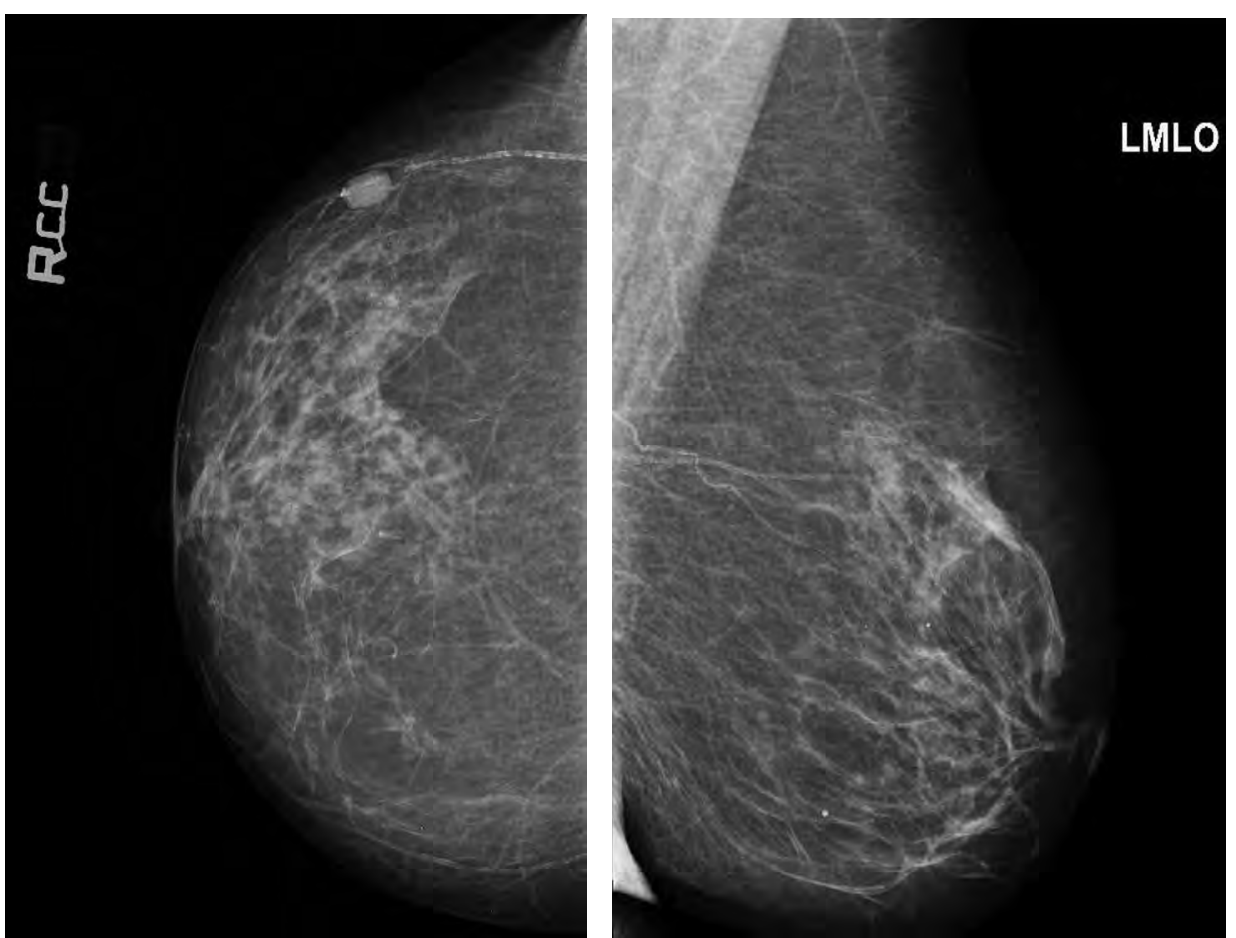

Right breast tumour Left breast

FIGURE 3. Mammogram 1 year later 


\section{REFERENCES}

1. Gheorghisan-Galateanu AA, Carsote M, Valea A. Incidentaloma: From general practice to specific endocrine frame. J Pak Med Assoc. 2017; 67(6):917-922.

2. Poiana C, Carsote M, Chirita C, Terzea D, Paun S, Beuran M. Giant adrenal cyst: Case study. J Med Life 2010;3(3):308-313.

3. Paduraru DN, Nica A, Carsote M, Valea A. Adrenalectomy for Cushing's syndrome: Do's and don'ts. Journal of Medicine and Life. 2016;4(9):334-341.

4. Calle-Toro JS, Kelly A, Ford EJ, Zemel BS, Schall JI, Adgent MA, Umbach DM, Rogan WJ, Stallings VA, Darge K, Kaplan SL. Incidental findings during ultrasound of thyroid, breast, testis, uterus and ovary in healthy term neonates. J Ultrasound. 2019;22(3):395-400.

5. Omar L, Gleason MK, Pfeifer CM, Sharma P, Kwon JK. Management of Palpable Pediatric Breast Masses With Ultrasound Characteristics of Fibroadenoma: A More Conservative Approach. AJR Am J Roentgenol. 2019;212(2):450-455.
6. Krings G, Bean GR, Chen YY. Fibroepithelial lesions; The WHO spectrum. Semin Diagn Pathol. 2017 Sep;34(5):438-452.

7. Tan BY, Tan PH. A Diagnostic Approach to Fibroepithelial Breast Lesions. Surg Pathol Clin. 2018;11(1):17-42.

8. Jung J, Kang E, Chae SM, Kim H, Park SY, Yun B, Kim SM, Jang M, Kim SW, Kim EK. Development of a Management Algorithm for the Diagnosis of Cellular Fibroepithelial Lesions From Core Needle Biopsies. Int J Surg Pathol. 2018;26(8):684-692.

9. Nie Y, Chen J, Huang D, Yao Y, Chen J, Ding L, Zeng J, Su S, Chao $\mathrm{X}$, Su F, Yao H, Hu H, Song E. Tumor-Associated Macrophages Promote Malignant Progression of Breast Phyllodes Tumors by Inducing Myofibroblast Differentiation. Cancer Res. 2017; 77(13):3605-3618

10. Poiana C, V.Radoi, Carsote M, Bilezekian J. New Clues that May Link Osteoporosis to the Circulating Lipid Profile. Bone Research 2013; 1(3):260-266. 